\title{
Feed-derived iodine overrides environmental contribution to cow milk
}

\author{
C. McKernan, C. Meharg, ${ }^{*}$ M. Carey, E. Donaldson, P. Williams, L. Savage, and A. A. Meharg* \\ Institute for Global Food Security, Queen's University Belfast, 19 Chlorine Gardens, Belfast, BT9 5DL, United Kingdom
}

\begin{abstract}
Diets worldwide are deficient in iodine, leading to a range of undesirable health effects at the population level. Dairy products are a primary source of iodine in diets for those populations in which iodized salt is not systematically used or available. However, the flows of iodine through dairy agroecosystems are not well understood. The aim of this research was to investigate iodine flows though the dairy agroecosystem, including the influence of atmospheric depositional inputs, environmental variables, season, husbandry, and diet. Three farm-based sampling campaigns were carried out in this investigation, with milk, soil, silage, grass, and feed iodine determined by inductively coupled plasma mass spectroscopy, and nonparametric statistical analysis tests were conducted on data sets obtained. Natural iodine inputs into the environment are dominated by atmospheric deposition, which mainly from sea spray, and thus the location of farms relative to the coast and prevailing wind direction. Herbage and silage produced from grass-based systems strongly correlated with soil iodine, yet there was a strong disconnect between soil, forage, and feed and the milk that results. This was due to the levels of iodine in supplemental feeds being approximately 10 -fold higher than those in forage-derived feeds. The practice of feed supplementation, accentuated by summer housing of cows, led to elevated milk iodine.
\end{abstract}

Key words: cow, iodine, milk, silage

\section{INTRODUCTION}

Iodine is an essential element that is widely deficient in the diet in numerous industrialized countries, including the United Kingdom, Ireland, Norway, New Zealand, and Australia (Nawoor et al., 2006; Zimmermann, 2011). Furthermore, vulnerable population groups, including females of childbearing age and preg-

\footnotetext{
Received August 13, 2019.

Accepted March 24, 2020.

*Corresponding authors: aa.meharg@qub.ac.uk and c.meharg@qub .ac.uk
}

nant women, are at risk of being iodine deficient in the United Kingdom and Ireland (Bath et al., 2014; Mullan et al., 2019). The most common and visible effect of iodine deficiency is goiter, the swelling of the thyroid gland observed in the neck (Hetzel, 1983). Another iodine deficiency disorder occurs during pregnancy, as the hormones produced by the thyroid gland are responsible for ensuring the normal development of the fetal brain and nervous system before birth (Patel et al., 2011). Pregnancy is a particularly important time because the thyroid gland is approximately $50 \%$ more active than usual to support hormone production essential for both the mother and fetus (NHMRC, 2010). Iodine deficiency is also problematic in animal production systems, leading to reduced fertility and health of offspring (Wichel et al., 1996).

Iodine atmospherically deposited into soil is the primary entry point of this nutrient into the terrestrial food chain in maritime-influenced habitats, with iodine being elevated in the marine ecosystem (Suess et al., 2019). Wet and dry deposited iodine is derived from sea spray in addition to marine biovolatilization (Smyth and Johnson, 2011). As sea spray has a relatively short range, soils in closer proximity to marine environments are enriched in this element (Smyth and Johnson, 2011). Terrestrial biovolatilization of iodine, and subsequent redeposition, is thought to be important in a continental setting (Suess et al., 2019).

Transfer of soil iodine from depositional inputs through crops, and subsequent animal farming production systems, is not well understood, yet this iodine flow is essential to our health and well-being. In particular, with respect to environmental drivers, it is not well understood how geographic location, soil factors (OM content, $\mathrm{pH}$ ), and plant assimilation interact (Bowley et al., 2019). Transfer into herbage for dairy cattle is particularly important, not just for the health of herds but also regarding iodine transfer into dairy products. Milk, yogurt, and cheese are primary sources of iodine in human diets (Nawoor et al., 2006; O'Brien et al., 2013). The dairy industry has become more intensive, with dairy cows increasingly housed either during winter or year-round and an increasing reliance on silage and feed supplement (DAERA, 2019; Smid et al., 2019). 
Furthermore, the routine use of disinfectant iodophors to clean teat and milk storage containers contributes to fluctuating milk iodine concentration (O'Brien et al., 2013). Research has demonstrated that the application of iodine to feed is reflected in milk iodine concentration (Flachowsky et al., 2014). Whereas essential vitamins and minerals are routinely added to silage in typical feeding systems, TMR, iodine is underinvestigated (Wichel et al., 1996; DAERA, 2019). Furthermore, the differences between summer pasture herds and herds housed year-round, summer versus winter housing (O'Brien et al., 2013), and the balance between grass, silage, and feed supplemented with iodine (Wichel et al., 1996; DAERA, 2019) make understanding iodine flows in agronomic systems complex.

Here we investigate iodine flows through a dairy agroecosystem, including the influence of depositional inputs, environment, husbandry, and diet. This was investigated in the northeast of Ireland for 2 reasons. First, Northern Ireland has a very well-characterized soil geochemistry, mapped at $2-\mathrm{km}^{2}$ resolution (British Geological Survey, 2016; see Figure 1). This mapping shows a strong gradient in iodine from the eastern coastline to the central landlocked midlands (Smyth and Johnson, 2011). Second, intensive large animal production systems, of which dairy and beef dominate, are the mainstay of the economy, and dairy farming is geographically widespread (Titterington et al., 2017), as illustrated by the distribution of our study farms (Figure 1). Here we use the northeastern Irish agronomic setting to test key issues regarding iodine in food chains.

\section{MATERIALS AND METHODS}

\section{Sample Collection}

Three experimental sampling campaigns are presented here: a detailed survey of dairy farms conducted over winter and summer, a more detailed investigation into cow husbandry practices, and determining iodine inputs from atmospheric deposition. Water samples were not analyzed in this study because various publications have identified that the iodine concentrations of water in the United Kingdom and Ireland are $<3 \mu \mathrm{g} / \mathrm{L}$ and are therefore unlikely to contribute to milk iodine concentrations (Dahl et al., 2003; Vanderpump et al., 2011; Mullan et al., 2019).

For the detailed farm-based campaigns, the initial sample collection was conducted in January to February 2016 for 71 farms across Northern Ireland (Figure 1 ). Samples were collected from enterprises focused on dairy production, with herd size ranging from 60 to 250 lactating cows. Additionally, all animals were housed in barns at least part of the year, with 65 herds being grazed during the more temperate months. For each farm, milk samples $(50 \mathrm{~mL})$ were collected from 6 randomly selected cows at milking to ascertain iodine variability within a herd. Samples were collected from individual homogenized sampling tanks to ensure that a representative milk sample was collected. Additionally, from each farm a composite sample of topsoil $(0-20 \mathrm{~cm})$ was collected using a soil corer (3-cm diameter) from 4 locations throughout the field to obtain a representative sample of the paddock. Furthermore, a forage grass sample was obtained from the respective paddock. Silage provided to the herd was also sampled, and to facilitate homogeneity, silage was collected from 5 regions throughout the feedbunk barn and combined and mixed to give a uniform sample. A second survey was conducted during July 2017 with a subset of 48 farms selected - those that grazed the cattle. This sampling campaign involved the sample collection of milk (50 $\mathrm{mL}$ ) from 6 randomly selected cows and a subsample of grass from a grazed paddock from each farm.

In addition to the winter $(\mathrm{n}=71)$ and summer ( $\mathrm{n}$ $=48$ ) sampling campaigns outlined, for the husbandry exploration, an additional 114 farms were recruited in Northern Ireland and surveyed during February 2019 to further investigate how feeding and hygiene, potential teat cleaning, and disinfection with iodophors affected milk iodine. Here, bulk tank milk per farm and feed provided to the herd were sampled. In addition to this sample collection, farmers were questioned on various husbandry practices, including teat hygiene practice, feed supplementation, and supplemental feed subsampled for analysis.

Iodine was measured in wet and dry deposition for a Northern Irish east coast rural location (54.617 N, $-5.817 \mathrm{~W}$ ) between Bangor and Belfast (Figure 1) during the summer and winter of 2015 to 2017, relevant to the time period when the main farm survey was conducted. Depositional sampling location and methodology are given in Savage et al. (2019).

\section{Sample Preparation}

Water, milk, soil, silage, and grass samples were stored at $-20^{\circ} \mathrm{C}$ for 3 mo during the collection period until subsequent analysis (Hansson et al., 2008). In preparation for iodine inductively coupled plasma MS quantification, all milk samples were freeze-dried overnight using a Christ Alpha 1-4 LD Plus freeze dryer (Christ, Osterode, Germany). Freeze-dried samples were then fat extracted via homogenization in a $2: 1$ petroleum ether:diethyl ether (BDH Dorset, Poole, UK) solution, generating a powdered milk sample. Samples of soil, silage, and grass were dried in an oven at $70^{\circ} \mathrm{C}$ 

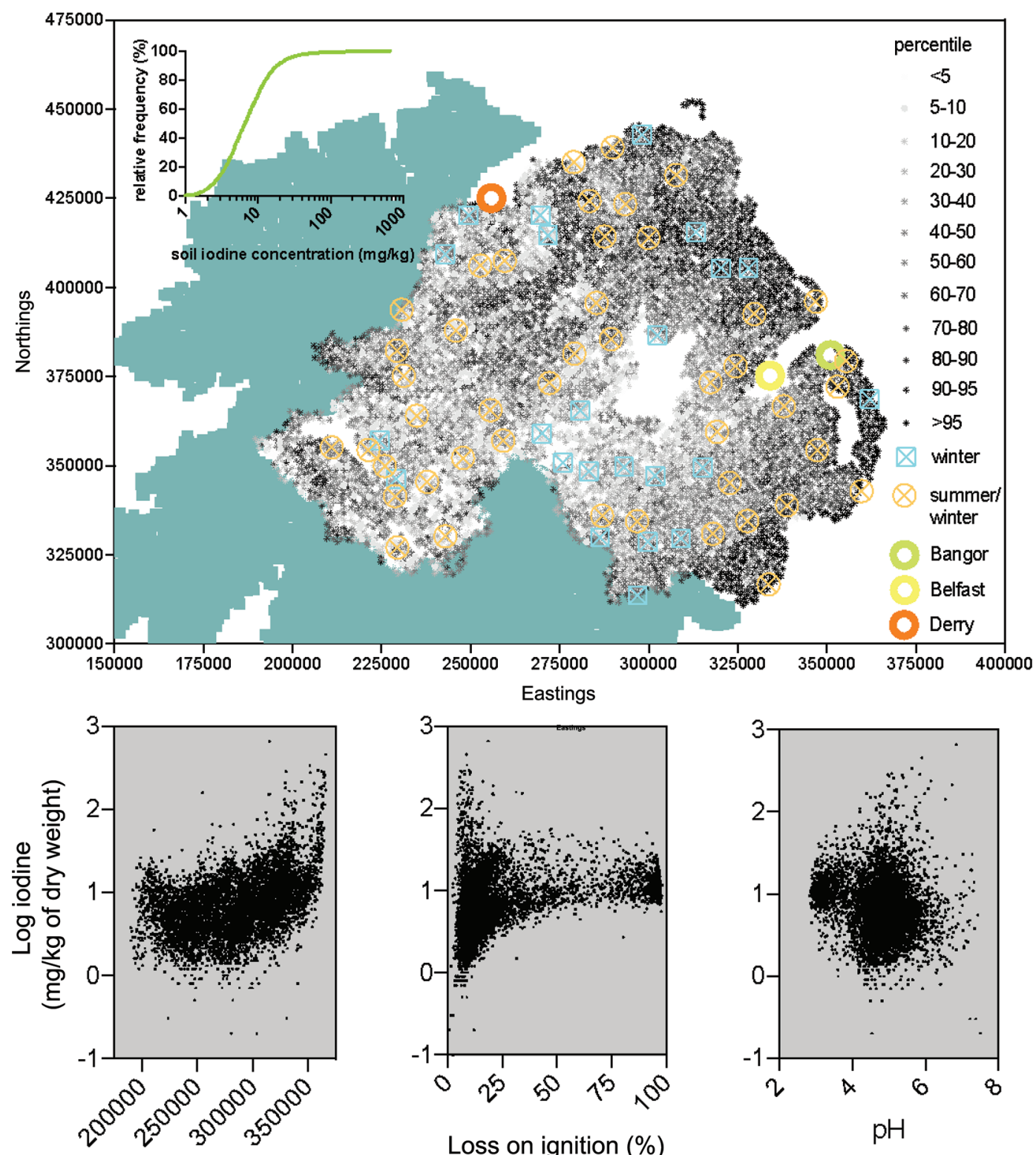

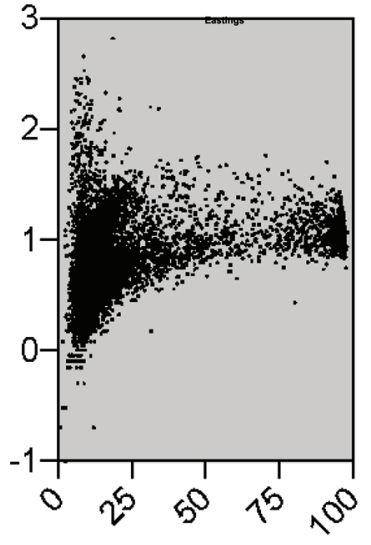

Loss on ignition (\%)

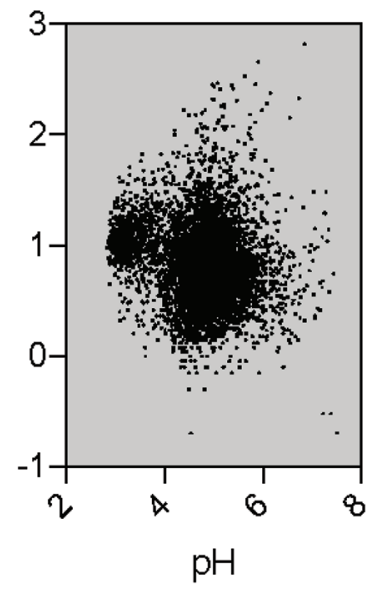

Eastings

Figure 1. Iodine distribution in percentiles for Northern Irish topsoils calculated from the concentration data in the British Geological Society (2016) database, overlaid with sample locations for the environmental sampling campaign. Circles are for summer pasture and winter housing, and squares are for year-round housing. Individual iodine percentile data are mapped. Note that the urban conurbations of Bangor, Belfast, and Derry were excluded from sampling. The inset shows the distribution of the percentile data. Below the map are plots of iodine concentration against eastings. Loss on ignition and $\mathrm{pH}$ are shown for individual Tellus data points.

overnight (N6S, Genlab, Widnes, UK). Once dried, the silage and grass samples were placed into a planetary ball mill (PM100 Ball Mill, Retsch, Haan, Germany) at $500 \mathrm{rpm}$ for $5 \mathrm{~min}$ to generate a homogeneous and representative powder. The soil was ground by hand using a mortar and pestle and passed through a 2-mm sieve.

Powdered milk, silage, and grass were accurately weighed to $100 \mathrm{mg}$, and $1 \mathrm{~mL}$ of $5 \%$ (wt/vol) tetramethylammonium hydroxide (TMAH) solution (Sig-
ma-Aldrich, St. Louis, MO) was added to each sample and allowed to sit overnight. Following this, $4.5 \mathrm{~mL}$ of standard deionized water $>18.2 \mathrm{M} \Omega \cdot \mathrm{cm}\left(\right.$ at $\left.25^{\circ} \mathrm{C}\right)$ was added to each sample, and samples were placed in a microwave (Mars 6 240150, CEM Microwave Technology, Buckingham, UK) for a 50-min cycle. To each sample, $10 \mu \mathrm{L}$ of the internal standard rhodium (Sigma-Aldrich) was added and samples were made up to $10 \mathrm{~mL}$ using standard deionized water. Milk samples 
Table 1. Iodine recoveries from certified reference material (CRM)

\begin{tabular}{lccccc}
\hline CRM & No. & $\begin{array}{c}\text { Certified value } \\
\text { of iodine } \\
(\mathrm{mg} / \mathrm{kg})\end{array}$ & $\begin{array}{c}\text { Limit of } \\
\text { detection } \\
(\mathrm{mg} / \mathrm{kg})\end{array}$ & $\begin{array}{c}\text { Mean iodine } \\
\text { recovered } \\
(\mathrm{mg} / \mathrm{kg})\end{array}$ & $\begin{array}{c}\text { CRM } \\
(\mathrm{mg} / \mathrm{kg})\end{array}$ \\
\hline Skim milk powder ERM BD151 & 78 & 1.78 & 0.232 & 1.48 & 0.162 \\
Citrus leaf NCS ZC73018 & 20 & 0.53 & 0.048 & 0.484 & 83 \\
Soil NCS ZC73007 & 6 & 1.3 & 0.139 & 1.1 & 0.071 \\
\hline
\end{tabular}

were centrifuged and filtered using a cellulose Steripop 0.45- $\mu \mathrm{m}$ express filter unit (Millex, Millipore, Billerica, MA). Finally, $3 \mathrm{~mL}$ of $0.5 \%$ TMAH solution was added to $3 \mathrm{~mL}$ of the filtered sample solution. Similarly, the soil, silage, and grass samples were centrifuged, and 1 in 10 dilutions was prepared with $0.5 \%$ TMAH. Iodine concentration in the digests was quantified by inductively coupled plasma MS (Icap Q, Thermo Scientific, Waltham, MA).

Blanks were prepared using standard $(10 \mathrm{~mL})$ deionized water $>18.2 \mathrm{M} \Omega \cdot \mathrm{cm}\left(\right.$ at $\left.25^{\circ} \mathrm{C}\right)$ in the same manner as samples prepared for each instrument run. The limit of detection was calculated as the average concentration in the blank +3 times the standard deviation for element mix. In addition to the blanks, certified reference materials (CRM) were completed in triplicate for each instrument run: skim milk powder (ERM BD151), soil (NCS ZC73007), and citrus leaf (NCS ZC73018). A citrus leaf CRM was used for vegetation because it is certified for iodine.

To determine the soil $\mathrm{pH}, 2 \mathrm{~g}$ of soil was added to 10 $\mathrm{mL}$ of deionized water $>18.2 \mathrm{M} \Omega \cdot \mathrm{cm}$, and the solutions were vortexed (DVX-2500 multitube vortex; VWR, Radnor, PA) at 1,500 rpm for $15 \mathrm{~min}$. Then, $\mathrm{pH}$ was measured using a VWR Phenomenal $\mathrm{pH} 100 \mathrm{H}$ instrument. Loss on ignition (LOI) was used to determine the OM content of the soil samples. Approximately 5 $\pm 1 \mathrm{~g}$ was accurately weighed into the crucible. This sample was placed into the muffle furnace (Carbolite, Hope, UK) at $500^{\circ} \mathrm{C}$ for $3 \mathrm{~h}$ and allowed to cool to ambient in a desiccator. The ashed sample and crucible were reweighed and recorded.

\section{Statistical Analysis}

Statistical analysis was conducted using GraphPad Prism (version 8.11; GraphPad, San Diego, CA). Initial ANOVA outputs found that the residuals were not normally distributed; therefore, nonparametric statistical tests were performed, including Mann-Whitney, Kruskal-Wallis, and 2-way ANOVA on ranked data. These statistical tests were performed for winter and summer and husbandry campaigns were completed and indicated, as such, throughout. In addition, log-transformation was used for any linear regression modeling.

\section{RESULTS}

\section{Environmental Survey}

The iodine concentrations in the CRM were above the limit of detection, with milk, vegetation, and soil recoveries of 83,91 , and $84 \%$, respectively (Table 1 ). The iodine concentrations of pasture soils ranged from 0.78 to $89.43 \mathrm{mg} / \mathrm{kg}$ of DM, a 100 -fold variation. The overall median iodine concentration of soil was 4.42 $\mathrm{mg} / \mathrm{kg}$ of DM. Linear regression analysis indicated that there was statistically significant variation in soil iodine concentrations longitudinally, increasing west to east, with no significant difference latitudinally (Figure 2). The LOI of the soil in this study ranged between 6 and $34 \%$, and linear regression analysis indicated that there was not a statistically significant relationship between soil iodine concentration and LOI. The $\mathrm{pH}$ levels of soils characterized here ranged from 4.1 to 6.9 , with no relationship between iodine concentrations in soils and $\mathrm{pH}$ of the soil.

Linear regression analysis illustrated a positive and highly significant relationship between soil and winter grass iodine concentration (Figure 2), but not with summer grass. Iodine concentrations in winter grass varied from 0.16 to $9.69 \mathrm{mg} / \mathrm{kg}$ of $\mathrm{DM}$, with a median iodine concentration of $0.86 \mathrm{mg} / \mathrm{kg}$ of DM; iodine concentrations in grass were approximately 5-fold lower than soils (Figure 3). Concentrations in summer grass were 2.4 times lower than those in winter grass, with concentrations ranging from 0.18 to $0.88 \mathrm{mg} / \mathrm{kg}$ of DM. Iodine concentrations in silage ranged from 0.10 to $10.25 \mathrm{mg} /$ $\mathrm{kg}$ of DM, with a median of $0.33 \mathrm{mg} / \mathrm{kg}$ (Figure 3). Further linear regression analysis found a statistically significant relationship in $\log _{10}$ iodine concentration between winter grass and silage and between winter grass and soil (Figure 2). A Mann-Whitney test found that the iodine concentration of silage was significantly lower than that of winter grass, but not summer grass, and that summer and winter grass were statistically different (Figure 3).

Milk iodine concentrations are reported on a DM basis, and the fresh weight (FW) iodine concentration of subsequent milks is provided in parentheses. There was no significant correlation between either summer 

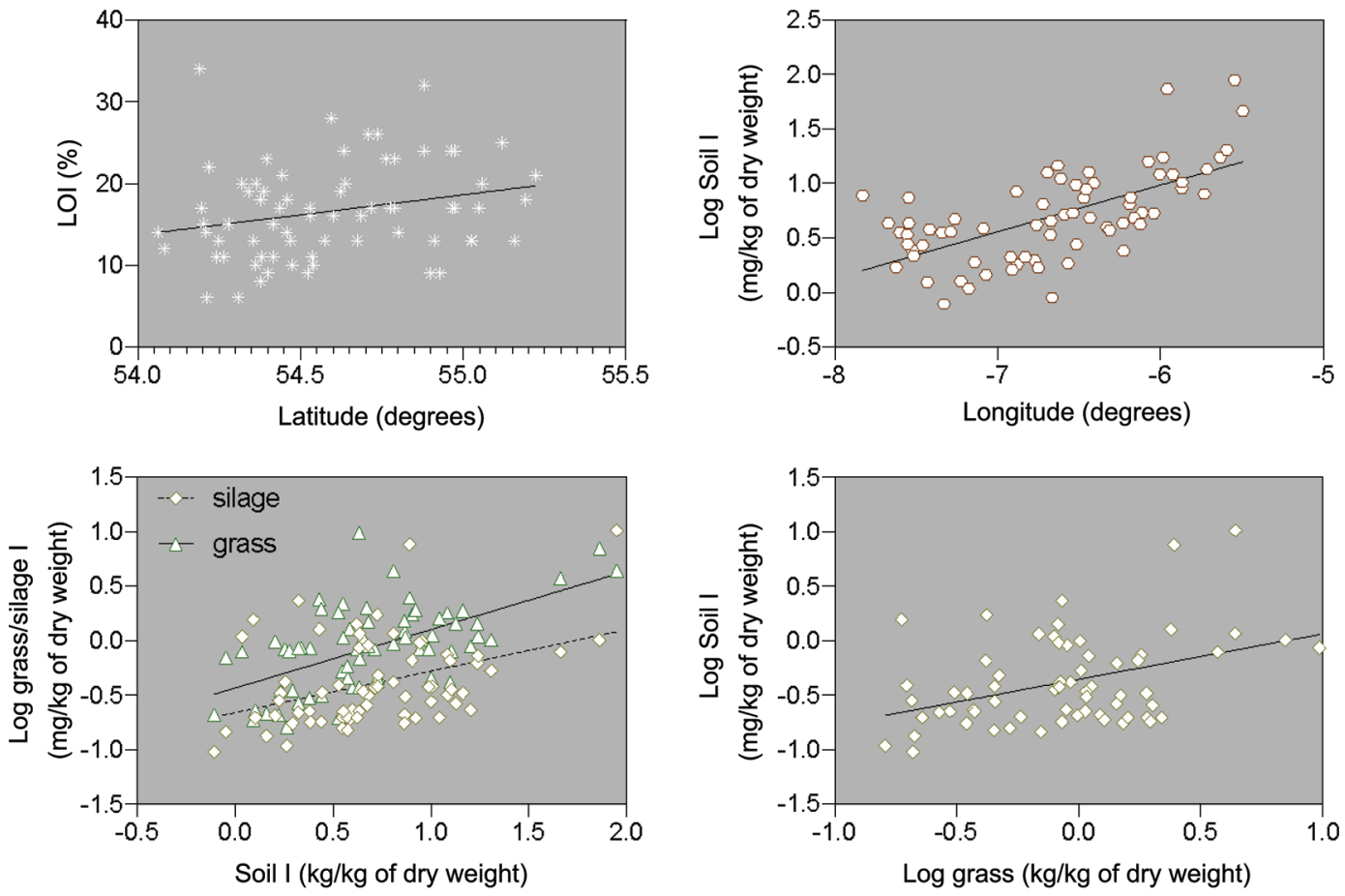

\begin{tabular}{|lllll|}
\hline Y-axis variable & X-axis variable & P-Values & $\mathbf{R}^{2}$ & Regression equation \\
\hline Soil LOI (\%) & Latitude & 0.0378 & 0.062 & $\mathrm{y}=0.049 \mathrm{x}-2.058$ \\
Soil iodine & Longitude & $<0.0001$ & 0.404 & $\mathrm{y}=0.4273 \mathrm{x}+3.548$ \\
Grass iodine & Soil iodine & $<0.0001$ & 0.346 & $\mathrm{y}=0.5363 \mathrm{x}-0.4352$ \\
Silage iodine & Soil iodine & 0.0009 & 0.158 & $\mathrm{y}=0.3796 \mathrm{x}-0.6599$ \\
Silage iodine & Grass iodine & 0.0009 & 0.162 & $\mathrm{y}=0.4176 \mathrm{x}-0.3547$ \\
\hline
\end{tabular}

Figure 2. Linear regression scatter graphs to demonstrate statistically significant relationships between various variables for pastures. LOI $=$ loss on ignition.

or winter milk with any environmental variable. Also, winter and summer milks were not significantly correlated with each other. A Mann-Whitney test found that median summer milk concentrations were approximately $50 \%$ of the same herds in the winter, 1.91 versus $3.87 \mathrm{mg} / \mathrm{kg}$ of DM (248 vs. $503 \mu \mathrm{g} / \mathrm{kg}$ of FW; Figure $3)$. Similar values were obtained from another study reporting median milk iodine concentrations of $3.43 \mathrm{mg} /$ $\mathrm{kg}$ of DM $(445.9 \mu \mathrm{g} / \mathrm{kg}$ of FW), which is comparable with the iodine concentrations present in this study (Travnicek et al., 2006). There was no statistical difference between winter milks for herds housed year-round versus those housed only in winter. A 2-way ANOVA found that different herds were significantly different in milk iodine for both summer and winter. Summer milk medians ranged from 0.32 to $13.73 \mathrm{mg} / \mathrm{kg}$ of DM $(41.6-1,784 \mu \mathrm{g} / \mathrm{kg}$ of $\mathrm{FW})$, and winter milk medians ranged from 1.19 to $18.65 \mathrm{mg} / \mathrm{kg}$ of DM $(155-2,424 \mu \mathrm{g} /$ $\mathrm{kg}$ of $\mathrm{FW}$ ). To consider the relationship between summer and winter milk produced from the same herds, the data were ranked by summer milk median concentration, and median and ranges were plotted for both seasons (Figure 4). This reveals that for 16 out of the 48 farms, medians were considerably lower during the summer compared with winter, with little or no overlap in range of concentrations found per herd. Then, at milk iodine concentrations of $1.26 \mathrm{mg} / \mathrm{kg}$ of DM (164 $\mu \mathrm{g} / \mathrm{kg}$ of $\mathrm{FW}$ ) and greater, there was little difference in milk iodine concentrations between summer and winter; summer milk exceeded that of winter milk in 10 cases out of 32 . The highest median iodine in milk for summer and winter occurred at the same farm. In contrast, the farm that provided the lowest summer milk had the third highest winter milk.

\section{Farm Practice Survey}

To follow up on the results of the environmental survey, 114 farms were investigated to relate milk iodine concentrations to cow husbandry, concentrating 
on where iodine may enter the food chain as feed or through routine hygiene treatment. For feed, only 3 out of the 114 farms surveyed fed seaweed supplements. The milk from these farms was not particularly elevated in iodine, ranging from 3.41 to $3.67 \mathrm{mg} / \mathrm{kg}$ of DM (443-447 $\mu \mathrm{g} / \mathrm{kg}$ of FW; Figure 3). More discriminatory with respect to milk iodine was whether postmilking iodine-based teat dips or sprays were used: median iodine in milk was $4.65 \mathrm{mg} / \mathrm{kg}$ of $\mathrm{DM}(604 \mu \mathrm{g} / \mathrm{kg}$ of $\mathrm{FW}$ ) when such dips and sprays were used compared with a median of $3.28 \mathrm{mg} / \mathrm{kg}$ of DM $(426 \mu \mathrm{g} / \mathrm{kg}$ of $\mathrm{FW}$ ) when non-iodine-based teat treatments were used; these differences were significant (Figure 3). A total of $34 \%$ of farms used iodine-based teat treatments. The medians of these winter milks were comparable with those of the wider geographical winter survey (Figure 3) and were significantly different compared with summer milk, containing approximately double the iodine concentration of summer milk.

On selected farms $(\mathrm{n}=25)$, supplemental feeds were collected for analysis. The range of iodine in feed blends (forage based) was greater than that in nuts (a common term in Irish husbandry referring to pelleted meal): 0.35 to 22.5 versus 0.44 to $10.1 \mathrm{mg} / \mathrm{kg}$ of $\mathrm{DM}$, respectively (Figure 3). The forage blend iodine concentrations were more skewed to low concentrations, whereas the reverse was true for meal. The median iodine in forage blend was $4.54 \mathrm{mg} / \mathrm{kg}$ of DM compared with $2.75 \mathrm{mg} / \mathrm{kg}$ of DM in meal, with no significant difference between both. These feed iodine contents were much higher than for silage (median: $0.33 \mathrm{mg} / \mathrm{kg}$ of $\mathrm{DM}$ ) or winter grass (median: $0.86 \mathrm{mg} / \mathrm{kg}$ of $\mathrm{DM}$ ).

\section{Depositional Inputs}

Concentrations of iodine inputted into the coastal plain (i.e., optimal iodine input scenario) are reported in Figure 5. Iodine input to soil surfaces is dominated by wet, as opposed to dry, deposition when paired by summer or winter season, for both seasons. Winter bulk deposition was significantly lower, by 2.5 -fold, compared with dry deposition, with dry deposition be-

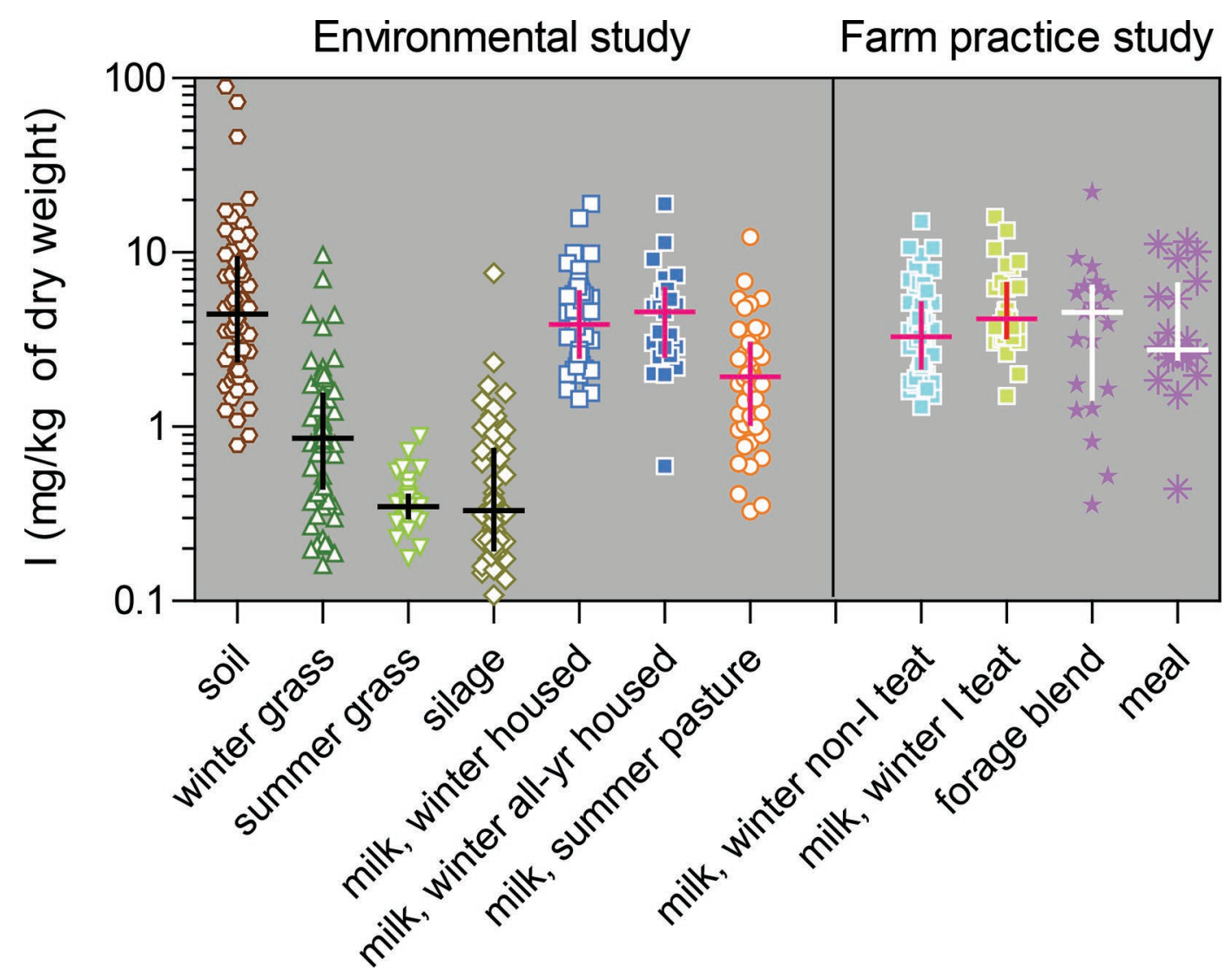

Figure 3. Environmental study: iodine concentration $(\mathrm{mg} / \mathrm{kg}$ of dry weight) of soil (hexagons, $\mathrm{n}=71)$; grass (triangles $=$ winter and inverted triangles = following summer, $\mathrm{n}=71$ ); silage (diamonds, $\mathrm{n}=71$ ); winter milk, housed just in winter (open squares, $\mathrm{n}=71$ ); winter milk, housed year-round (closed dark blue squares, $\mathrm{n}=60$ ), and summer milk, pasture-fed (circles, $\mathrm{n}=48$ ). Farm practice study $(\mathrm{n}=114)$ : iodine concentration $(\mathrm{mg} / \mathrm{kg}$ of dry weight) of winter milk, absence of teat dipping (turquoise squares); winter milk, presence of post-teat dipping (green squares); cattle forage blend (stars); and meal (asterisks). Horizontal bars are medians, and vertical bars are the inter-quartile range. 
ing $40 \%$ lower in winter compared with summer. There was no significant difference in bulk deposition between years for the summer season.

\section{DISCUSSION}

The British Geological Survey Tellus map of Northern Ireland shows the gradient in topsoil iodine concentration from the east coast to the central midlands (Figure 1). Even though the prevailing wind is westerly (i.e., from the Atlantic Ocean), the central midlands are in the lee of the mountainous coast counties of Donegal and Sligo to the west. Farm sampling sites are overlain over the iodine map, showing the even distribution across the study area. Plots of iodine against eastings show the decrease in iodine from east to west. Iodine is associated with OM, increasing an order of magnitude in peat soils compared with the low-OM $(<5-10 \%$ LOI) soils. However, the highest iodine concentrations ( $>5 \mathrm{mg} / \mathrm{kg}$ iodine, the median soil concentration) are found in low-OM soils. This is because low-OM soils (i.e., sands and gravels) are typically found in coast regions where high iodine deposition occurs. Thus, 2 factors dominate iodine accumulation in soils: (1) the OM content, with OM also associated with higher rainfall and thus higher potential depositional inputs, and (2) the geographic proximity to the coast. This balance between location and soil characteristics can also be seen in the relationship between soil iodine and $\mathrm{pH}$, where low soil $\mathrm{pH}$ (i.e., peats) have high iodine, but with a much wider spread of iodine concentrations as soil $\mathrm{pH}$ increases.

This investigation found that although there was a strong link between region (longitude), soil, winter grass, and silage iodine, there was a considerable disconnect between environmental iodine and milk concentrations. From follow-up on farms, this was due to both iodine used in teat cleaning on one-third of farms, leading to a $30 \%$ increase in milk iodine on those farms, and to generally high iodine in supplemental feeds. During winter milk iodine concentrations were universally high across all farms, whereas during summer when cows were in pasture the farms were split into low and high milk iodine. Silage and summer forage, from which silage is produced, were low in iodine compared with supplemental feed and winter forage. Generally, iodine was deficient in grass compared with supplemental feed, despite northeastern Ireland being located on the coastal plain and having high iodine depositional inputs and large iodine reserves in soil.

Northern Ireland has a maritime-dominated weather pattern and is not considered an iodine-deficient environment, with a median value of $11 \mathrm{mg} / \mathrm{kg}$ for topsoil compared with a median of $6 \mathrm{mg} / \mathrm{kg}$ for Europe (Smyth and Johnson, 2011). This current study found a median of $4.4 \mathrm{mg} / \mathrm{kg}$ for pasture soils. The gradient in decreas-

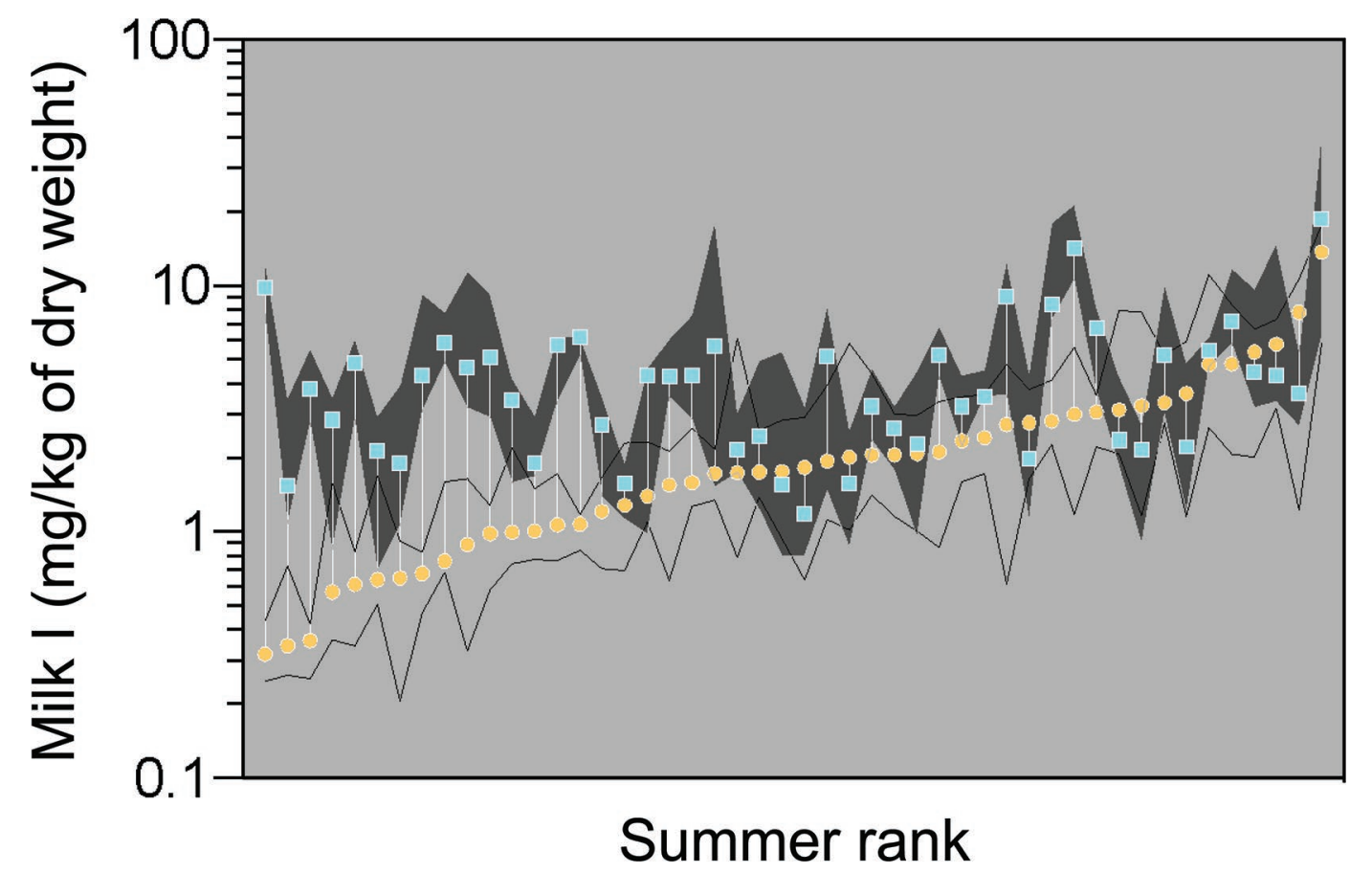

Figure 4. Iodine concentration ( $\mathrm{mg} / \mathrm{kg}$ of dry weight) in winter and subsequent summer milk ranked in order of summer milk concentrations. Turquoise squares are the winter milk median per farm, and the winter farm data range is given by the dark gray shading. Orange circles are the summer medians, and the black lines demarcate the summer range. 
ing soil iodine with longitude on an east-to-west basis agrees with previous literature, as the east is coastal and the west is inland and soil iodine concentration is elevated in coastal regions due to the atmospheric deposition of iodine from sea spray (Fuge and Johnson, 1986; Smyth and Johnson, 2011). Other factors regulating soil iodine, such as soil $\mathrm{pH}, \mathrm{OM}$ content, and texture, are important in respect to the concentration of iodine inputted to the soil. That is, peat soils have higher atmospheric inputs and the ability to retain iodine (Dai and Huang, 2006). However, for pasture soils, we found no relationship between soil iodine concentration and both the OM content and $\mathrm{pH}$ of soils, conflicting with the literature (Dai and Huang, 2006; Hong et al., 2008). This may be because pasture soils are only a subset of the wide soil diversity; that is, that they are selected and managed (through liming, fertilization, and drainage) for optimal forage production (Haynes and Naidu, 1998; Stockfisch et al., 1999).

Winter, but not summer, grass iodine concentrations correlated with those concentrations in soil for the investigation presented here, as observed by other investigators who also found the same relationship (McGrath and Fleming, 1988; Bowley et al., 2017). The results of the current study found that the iodine levels in grass collected varied from 0.16 to $9.69 \mathrm{mg} /$

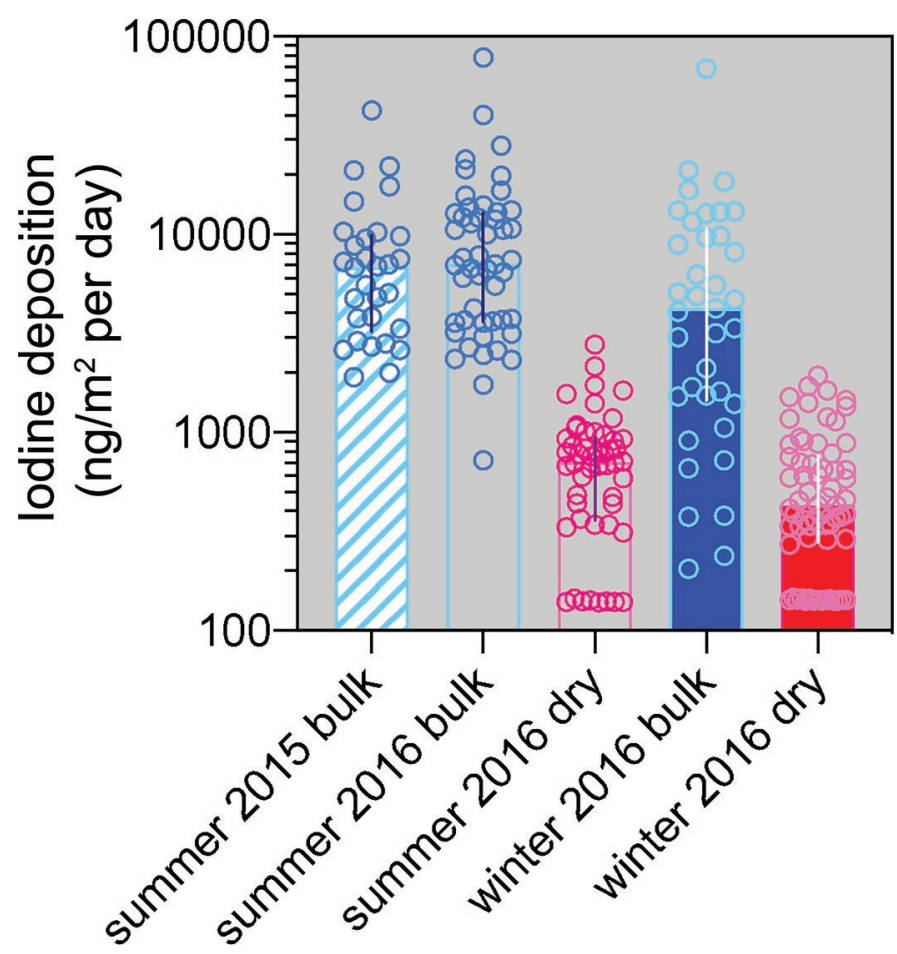

Figure 5. Iodine concentration in wet and dry deposition from the agronomic coastal plain of Northern Ireland with median (bars) and interquartile (lines) given. $\mathrm{kg}$, with a median iodine concentration of $0.86 \mathrm{mg} /$ kg. McGrath and Fleming (1988) found similar results, where herbage iodine ranged from 0.08 to $0.42 \mathrm{mg} / \mathrm{kg}$. These are similar to the summer observations reported in the current study. Here we observed a relationship between soils, winter grass, and silage but not summer herbage. This is because forage grows more slowly in winter than in summer (10 vs. $60 \mathrm{~kg}$ of DM/ha per day; Bowley et al., 2017; Agriland, 2019) and therefore has less growth dilution. Silage iodine concentrations, though prepared from summer grass, also related back to soil. Summer grass concentrations did not significantly correlated with soil, likely because of the higher yield and because each farm has a different grazing or silage-cutting pattern during the summer, whereas winter grass is more variable because it is rarely grazed or cut. Median concentrations did not differ much between summer grass and silage, showing that little iodine loss occurs during silage production. Silage measurements of iodine are rarely reported, let alone the underlying factors that give rise to silage iodine content. Travnicek et al. (2004) found that silage concentrations of iodine in Czech Republic silage at $0.169 \mathrm{mg} / \mathrm{kg}$ of DM, whereas grass from the same region had lower concentrations at $0.105 \mathrm{mg} / \mathrm{kg}$. Schöne et al. (2009) reported concentrations for German silage, $0.32 \mathrm{mg} / \mathrm{kg}$ of DM, similar to those reported here. Given that silage is the predominant feed source provided to cattle in modern farming practice (Weinberg and Muck, 1996; DAERA, 2019), the risk of iodine deficiency is a widespread and persisting issue for beef and milk herds (Wichel et al., 1996; Rogers and Gately, 1999; NRC, 2001). A significant proportion of feed provided to herds in this study fell below recommended iodine concentrations from National Research Council (0.5 mg/kg; NRC, 2001) and Irish recommendations $(0.9-3.6 \mathrm{mg} / \mathrm{kg}$; Rogers and Gately, 1999). In this study, we found that depositional inputs approximately matched grass offtake, yet this depositional input was only $0.04 \%$ per season of total soil iodine reserves. This agrees with a study looking at long-term inputs and outputs of iodine into UK pastures (Bowley et al., 2017). This reinforces the view that iodine species, primarily iodide and iodate, are immobile in soils (Takeda et al., 2015), and thus iodide predominantly present in fresh depositional inputs is the driver of iodine transfer into vegetation (Gilfedder et al., 2008; Suess et al., 2019). To place the depositional findings in context, they can be considered with respect to soil stores and grass offtake. The volume of soil in topsoil is approximately $250 \mathrm{~kg} / \mathrm{m}^{2}$ (Bowley et al., 2017). Using the soil median iodine concentrations from Figure 2, 1,102 $\mathrm{mg}$ of iodine is present in that square meter of topsoil. Summer deposition was 0.42 $\mathrm{mg} / \mathrm{m}^{2}, 0.04 \%$ of that pool. 
Despite the strong environmental relationships regarding iodine in soil and in herbage, there appears to be a disconnect in relation to milk iodine concentrations. Median milk iodine concentrations from this study showed considerable variation between farms, confirming previous study findings (Lee et al., 1994; Bath et al., 2012; Payling et al., 2015). Several studies have observed that the iodine concentration in milk has significantly increased in the past $30 \mathrm{yr}$ (Lee et al., 1994; Dahl et al., 2003; Soriguer et al., 2011). The present elevated iodine concentration in milk is thought to be due to the increased use of supplementation in farming. There is evidence that some pasture-based systems (e.g., white clover) contain goitrogenic compounds such as glucosinolates (Franke et al., 2009). These compounds have the ability to bind iodine, limiting transfer to milk, thus reducing milk iodine concentration. However, this is not an issue in Irish agronomic systems because the dominant source for forage and silage is perennial ryegrass (Franke et al., 2009; DAFM, 2018). There is unequivocal evidence that the season of milk production influences the iodine concentrations in milk, with the literature frequently reporting higher milk iodine concentrations in winter months (Flachowsky et al., 2014). This is due to enhanced supplementation during winter housing (Lee et al., 1994; O'Kane et al., 2018). Milk iodine concentrations observed in the current study displayed a seasonal variation similar to a previous Irish study reporting significantly higher milk iodine concentrations during winter months compared with summer (O'Brien et al., 2013; O'Kane et al., 2018). From the investigation presented here, it is clear that feed supplements are the dominant source of iodine in milk, overriding forage grass and silage contributions. Disinfectant iodophors used to disinfect teats postmilking (O'Brien et al., 2013) also led to elevation of iodine in approximately $30 \%$ of animals. The European Food Standards agency published a report in 2013 proposing that the authorized maximum levels of iodine should be reduced from $5 \mathrm{mg}$ of iodine $/ \mathrm{kg}$ of DM in dairy herd feed (EFSA, 2013). Furthermore, the National Research Council recommended that the iodine concentration in feed to meet requirements for lactating dairy cattle should be $0.5 \mathrm{mg} / \mathrm{kg}$ of DM (NRC, 2001). These recommendations (NRC, 2001; EFSA, 2013) were not due to risk of toxicity. For example, Schöne et al. (2009) did not observe detrimental effects in ruminants provided $>10 \mathrm{mg} / \mathrm{kg}$ of DM. These recommendations were to eliminate the occurrence of elevated milk iodine concentrations exceeding the upper limit in milk (600 and $200 \mu \mathrm{g} / \mathrm{d}$ for adults and toddlers, respectively; EFSA, 2013). This demonstrates the importance of getting the balance right for ruminant and human health because milk is the main source of iodine in the diet.

\section{CONCLUSIONS}

Despite strong environmental iodine relationships, there appeared to be a disconnect in relation to milk iodine and the environment. Ultimately, variable farm management practices such as feed supplementation and the use of teat iodophors contribute to variable milk iodine concentrations. To mitigate fluctuating milk iodine concentrations, consistent feed practices and continuous monitoring of milk iodine concentration are needed to alleviate deficiency and reduce the likelihood of toxicity.

\section{ACKNOWLEDGMENTS}

We thank the farmers and dairies who participated in this study. The Department of Agriculture and $\mathrm{Ru}-$ ral Development, Northern Ireland, is acknowledged for funding Claire McKernan. The British Geological Survey (Keyworth, Nottingham) and Geological Survey of Northern Ireland (Belfast) are thanked for provision of the publicly available Tellus data sets. The authors have not stated any conflicts of interest.

\section{REFERENCES}

Agriland. 2019. Grass growth: Feeling the squeeze. Accessed 2019. https://www.agriland.ie/farming-news/grass-growth-feeling-the -squeeze/.

Bath, S. C., S. Button, and M. Rayman. 2012. Iodine concentration of organic and conventional milk: Implications for iodine intake. Br. J. Nutr. 107:935-940. https://doi.org/10.1017/S0007114511003059.

Bath, S. C., A. Walter, A. Taylor, J. Wright, and M. P. Rayman. 2014. Iodine deficiency in pregnant women living in the South East of the UK: The influence of diet and nutritional supplements on iodine status. Br. J. Nutr. 111:1622-1631. https://doi.org/10.1017/ S0007114513004030.

Bowley, H. E., A. W. Mathers, S. D. Young, A. J. MacDonald, E. L. Ander, M. J. Watts, F. J. Zhao, S. P. McGrath, N. M. J. Crout, and E. H. Bailey. 2017. Historical trends in iodine and selenium in soil and herbage at the Park Grass Experiment, Rothamsted Research, UK. Soil Use Manage. 33:252-262. https://doi.org/10 .1111/sum.12343.

Bowley, H. E., S. D. Young, E. L. Ander, N. M. J. Crout, M. J. Watts, and E. H. Bailey. 2019. Iodine bioavailability in acidic soils of Northern Ireland. Geoderma 348:97-106. https://doi.org/10.1016/ j.geoderma.2019.04.020.

British Geological Society. 2016. Tellus Survey, Northern Ireland. Accessed 2019. https://www.opendatani.gov.uk/dataset/rural-soil -survey.

DAERA (Department of Agriculture, Environment and Rural Affairs). 2019. Silage management. Accessed Oct. 16, 2019. https://www .daera-ni.gov.uk/articles/silage-management.

DAFM (Department of Agriculture, Food and the Marine). 2018. Grass and white clover varieties. Accessed Jan. 22, 2020. https: //www.agriculture.gov.ie/media/migration/publications/2018/ GrassWhiteCloverRecListVarietiesforIreland220218.pdf.

Dahl, L., J. A. Opsahl, H. M. Meltzer, and K. Julshamn. 2003. Iodine concentration in Norwegian milk and dairy products. Br. J. Nutr. 90:679-685. https://doi.org/10.1079/BJN2003921.

Dai, W., and Y. Huang. 2006. Relation of soil organic matter concentration to climate and altitude in zonal soils of China. Catena 65:87-94. https://doi.org/10.1016/j.catena.2005.10.006. 
FEEDAP (EFSA Panel on Additives and Products or Substances used in Animal Feed). 2013. Scientific opinion on the safety and efficacy of iodine compounds (E2) as feed additives for all species: Calcium iodate anhydrous (coated granulated preparation), based on a dossier submitted by Doxal Italia S.p.A. Eur. J. Food Sci. Agric. 11:3178.

Flachowsky, G., K. Franke, U. Meyer, M. Leiterer, and F. Schöne. 2014. Influencing factors on iodine content of cow milk. Eur. J. Nutr. 53:351-365. https://doi.org/10.1007/s00394-013-0597-4.

Franke, K., U. Meyer, H. Wagner, H. O. Hoppen, and G. Flachowsky. 2009. Effect of various iodine supplementations, rapeseed meal application and two different iodine species on the iodine status and iodine excretion of dairy cows. Livest. Sci. 125:223-231. https:// doi.org/10.1016/j.livsci.2009.04.012.

Fuge, R., and C. C. Johnson. 1986. The geochemistry of iodine-A review. Environ. Geochem. Health 8:31-54. https://doi.org/10.1007/ BF02311063.

Gilfedder, B. S., S. C. Lai, M. Petri, H. Biester, and T. Hoffmann. 2008. Iodine speciation in rain, snow and aerosols. Atmos. Chem. Phys. 8:6069-6084. https://doi.org/10.5194/acp-8-6069-2008.

Hansson, M., M. Isaksson, and G. Berg. 2008. Sample preparation for in vitro analysis of iodine in thyroid tissue using X-ray fluorescence. Cancer Inform. 6:51-57. https://doi.org/10.1177/ 117693510800600004.

Haynes, R. J., and R. Naidu. 1998. Influence of lime, fertilizer and manure applications on soil organic matter content and soil physical conditions: A review. Nutr. Cycl. Agroecosyst. 51:123-137. https:/ /doi.org/10.1023/A:1009738307837.

Hetzel, B. S. 1983. Iodine deficiency disorders (IDD) and their eradication. Lancet 2:1126-1129. https://doi.org/10.1016/S0140 -6736(83)90636-0.

Hong, C. L., H. X. Weng, Y. C. Qin, A. L. Yan, and L. L. Xie. 2008. Transfer of iodine from soil to vegetables by applying exogenous iodine. Agron. Sustain. Dev. 28:575-583. https://doi.org/10.1051/ agro:2008033.

Lee, S. M., J. Lewis, D. Buss, G. Holcombe, and P. Lawrance. 1994. Iodine in British foods and diets. Br. J. Nutr. 72:435-446. https:/ /doi.org/10.1079/BJN19940045.

McGrath, D., and G. A. Fleming. 1988. Iodine levels in Irish soils and grasses. Isr. J. Agric. Res. 27:75-81.

Mullan, K., L. Hamill, K. Doolan, I. Young, P. Smyth, A. Flynn, J. Walton, A. A. Meharg, M. Carey, C. McKernan, M. Bell, N. Black, U. Graham, D. McCance, C. McHugh, P. McMullan, S. McQuaid, A. O'Loughlin, A. Tuthill, S. C. Bath, M. Rayman, and J. V. Woodside. 2019. Iodine status of teenage girls on the island of Ireland. Eur. J. Nutr. https://doi.org/10.1007/s00394-019-02037-x.

NHMRC (National Health and Medical Research Council). 2010. Iodine supplementation for pregnant and breastfeeding women. Accessed 2020. https://www.nhmrc.gov.au/about-us/publications/ iodine-supplementation-pregnant-and-breastfeeding-women.

NRC (National Research Council). 2001. Nutrient Requirements of Dairy Cattle. 7th rev. ed. Natl. Acad. Press, Washington, DC.

Nawoor, Z., R. Burns, D. Smith, S. Sheehan, C. O'Herlihy, and P. Smyth. 2006. Iodine intake in pregnancy in Ireland-A cause for concern? Ir. J. Med. Sci. 175:21-24. https://doi.org/10.1007/ BF03167943.

O'Brien, B., D. Gleeson, and K. Jordan. 2013. Iodine concentrations in milk. Ir. J. Agric. Food Res. 52:209-216.

O'Kane, S. M., L. Pourshahidi, M. Mulhern, R. Weir, S. Hill, J. O'Reilly, D. Kmiotek, C. Deitrich, E. Mackle, E. Fitzgerald, C. Lowis, M. Johnston, J. J. Strain, and A. Yeates. 2018. The effect of processing and seasonality on the iodine and selenium concentration of cow's milk produced in Northern Ireland (NI): Implications for population dietary intake. Nutrients 10:287-301. https://doi .org/10.3390/nu10030287.

Patel, J., K. Landers, H. Li, R. Mortimer, and K. Richard. 2011. Thyroid hormones and fetal neurological development. J. Endocrinol. 209:1-8. https://doi.org/10.1530/JOE-10-0444.

Payling, L. M., D. Juniper, C. Drake, C. Rymer, and D. Givens. 2015. Effect of milk type and processing on iodine concentration of organic and conventional winter milk at retail: Implications for nutrition. Food Chem. 178:327-330. https://doi.org/10.1016/j .foodchem.2015.01.091.

Rogers, P. A., and T. F. Gately. 1999. Control of Mineral Imbalances in Cattle and Sheep: A Reference Manual for Advisers and Vets. Teagasc, Carlow, Ireland.

Savage, L., M. Carey, P. N. Williams, and A. A. Meharg. 2019. Maritime deposition of organic and inorganic arsenic. Environ. Sci Technol. 53:7288-7295. https://doi.org/10.1021/acs.est.8b06335.

Schöne, F., M. Leiterer, P. Lebzien, D. Bemmann, M. Spolders, and G. Flachowsky. 2009. Iodine concentration of milk in a dose-response study with dairy cows and implications for consumer iodine intake. J. Trace Elem. Med. Biol. 23:84-92. https://doi.org/10.1016/j .jtemb.2009.02.004.

Smid, A. M. C., E. E. A. Burgers, D. M. Weary, E. A. M. Bokkers, and M. A. G. von Keyserlingk. 2019. Dairy cow preference for access to an outdoor pack in summer and winter. J. Dairy Sci 102:1551-1558. https://doi.org/10.3168/jds.2018-15007.

Smyth, D., and C. Johnson. 2011. Distribution of iodine in soils of Northern Ireland. Geochem. Explor. Environ. Anal. 11:25-39. https://doi.org/10.1144/1467-7873/09-015.

Soriguer, F., C. Gutierrez-Repiso, S. Gonzalez-Romero, G. Olveira, M. J. Garriga, I. Velasco, P. Santiago, G. M. de Escobar, E. GarciaFuentes, and Iodine Deficiency Disorders Group of Spanish Society of Endocrinology and Nutrition. 2011. Iodine concentration in cow's milk and its relation with urinary iodine concentrations in the population. Clin. Nutr. 30:44-48. https://doi.org/10.1016/ j.clnu.2010.07.001.

Stockfisch, N., T. Forstreuter, and W. Ehlers. 1999. Ploughing effects on soil organic matter after twenty years of conservation tillage in Lower Saxony, Germany. Soil Tillage Res. 52:91-101. https://doi .org/10.1016/S0167-1987(99)00063-X.

Suess, E., F. Aemisegger, J. Sonke, M. Sprenger, H. Wernli, and L. H. E. Winkel. 2019. Marine versus continental sources of iodine and selenium in rainfall at two European high-altitude locations. Environ. Sci. Technol. 53:1905-1917. https://doi.org/10.1021/acs .est.8b05533.

Takeda, A., H. Tsukada, Y. Takaku, and S. Hisamatsu. 2015. Effect of aging on availability of iodine in grassland soil collected in Rokkasho Japan. J. Radioanal. Nucl. Chem. 303:1191-1195. https: //doi.org/10.1007/s10967-014-3457-7.

Titterington, F. M., F. O. Lively, A. Ashfield, A. W. Gordon, D. E. Lowe, and S. J. Morrison. 2017. Impacts of on farm management factors on herd fertility of commercial beef breeding herds in Northern Ireland. J. Agric. Sci. 155:1005-1021. https://doi.org/10 $.1017 /$ S0021859617000211.

Travnicek, J., I. Herzig, J. Kursa, V. Kroupova, and M. Navratilova. 2006. Iodine content in raw milk. Veterinarni Medicina 51:448453. https://doi.org/10.17221/5574-VETMED.

Travnicek, J., V. Kroupova, and M. Soch. 2004. Iodine content in bulk feeds in western and southern Bohemia. Czech J. Anim. Sci. 49:483-488. https://doi.org/10.17221/4335-CJAS.

Vanderpump, M. P., J. H. Lazarus, P. P. Smyth, P. Laurberg, R. L. Holder, K. Boelaert, J. A. Franklyn, and British Thyroid Association UK Iodine Survey Group. 2011. Iodine status of UK schoolgirls: A cross-sectional survey. Lancet 377:2007-2012. https://doi .org/10.1016/S0140-6736(11)60693-4.

Weinberg, Z. H., and R. E. Muck. 1996. New trends and opportunities in the development and use of inoculants for silage. FEMS Microbiol. Rev. 19:53-68. https://doi.org/10.1111/j.1574-6976.1996 .tb00253.x.

Wichtel, J. J., A. L. Craigie, D. A. Freeman, H. Varela-Alvarez, and N. B. Williamson. 1996. Effect of selenium and iodine supplementation on growth rate and on thyroid and somatotropic function in dairy calves at pasture. J. Dairy Sci. 79:1865-1872. https://doi .org/10.3168/jds.S0022-0302(96)76554-2.

Zimmermann, M. B. 2011. Iodine deficiency in industrialized countries. Clin. Endocrinol. (Oxf.) 75:287-288. 